Research Article

\title{
JITTER ÖLÇÜMÜNDE ÖNEMLİ BİR GÖSTERGE: ARDIŞIK BLOKLAR
}

\section{N. Tuğrul ARTUĞ ${ }^{1 *}$, Sezin Alpaydın BASLO², M. Barış BASLO ${ }^{3}$}

1 İstanbul Arel Üniversitesi, Mühendislik-Mimarlık Fakültesi, Elektrik-Elektronik Mühendisliği Bölümü, İstanbul, Türkiye

${ }^{2}$ Sağlık Bilimleri Üniversitesi, Bakırköy Prof. Dr. Mazhar Osman Ruh Sağlığı ve Sinir Hastalıkları Eğitim ve Araștırma Hastanesi, İstanbul, Türkiye

3 İstanbul Üniversitesi, İstanbul Tıp Fakültesi, İstanbul, Türkiye

\begin{tabular}{l}
\hline Anahtar Kelimeler \\
\hline Elektromiyografi, \\
Jitter, \\
Ardıssılk Bloklar, \\
Biyomedikal İşaret Isşleme.
\end{tabular}

$\ddot{0} \mathbf{z}$

Nöromüsküler hastalıklar sinirden kasa iletimi etkilerler. Eğer bir sinir uyartı eşik değerinden daha yüksek bir uyartı ile uyarılırsa aksiyon potansiyeli üretilir. Sinirden kasa doğru aksiyon potansiyelinin iletimi 0.5 ile $1 \mathrm{~ms}$ arasında bir zaman almaktadır. Bu zaman uyarıdan uyarıya değişmektedir ve bu değişintiye "Jitter" adı verilir. Ardışık sinir uyartımına karşılık üretilen yanıt uyartı ile birlikte tek lif EMG elektrodu ile kaydedilir. Bazı ülkelerdeki kısıtlamalardan dolayı tek kullanımlık konsantrik elektrot da jitter ölçümü için kullanılmaktadır. Zaman zaman kayıtlarda sinir uyartımına karşılık yanıt alınamaz ve bloklar gözlemlenir. Ardışı uyarıya karşılık hasta kayıtlarında blokları görmek mümkündür. Bu çalışmada 13 katılımcıdan konsantrik iğne elektrodu kullanarak her oturumda 100 sinyal kaydedilmiştir ve geliştirilen yazılım ile bu kayıtlar analiz edilmiştir. Bu yazılımla, jitter değeri ve blok sayısı hesaplanabilirken, ardıșık bloklar da gösterilebilmektedir. Sağlıklı bireylerde hiç blok görülmemiştir fakat miyasteni gravis hastalarında yüksek miktarda blok ve ardışık blok grubu görülmüştür. Blok sayısındaki artma ve ardışık blok gruplarındaki artışın hastalı̆̆ın ciddiyeti konusunda bir gösterge olacağı öngörülmüștür.

\section{AN IMPORTANT INDICATOR IN JITTER MEASUREMENT: CONSECUTIVE BLOCKS}

\section{Keywords \\ Electromyography, \\ Jitter, \\ Consecutive Blocks, Biomedical Signal Processing.}

\begin{abstract}
Neuromuscular diseases affect the transmission from nerve to muscle. If the nerve is stimulated above the threshold, action potential is produced. The transmission of action potential from nerve to muscle takes about 0.5 to $1 \mathrm{~ms}$. This time varies from stimulus to stimulus. This variability is called as "Jitter". The stimulus and response to the consecutive nerve stimuli are recorded with single fiber EMG electrode. Because of restrictions in some countries, disposable concentric needle electrode is also used for jitter measurement recently. Sometimes the response to nerve stimulus is not observed and blocks are presented in recordings. It is possible to see them in patient recordings against consecutive stimuli. In this study, 100 signals are recorded in each session from different sites of 13 participants by using concentric needle electrode and they are analyzed with the developed software. Jitter value can be calculated and number of blocks with consecutiveness of impulse blockings can be demonstrated. No blocks were observed in healthy individuals but high number of blocks and consecutive block groups were observed in myasthenia gravis patients. The increase in number of blocks and excess of consecutive block groups are foreseen as an indicator about the severity of disease.
\end{abstract}

\footnotetext{
Alıntı / Cite

Artuğ, N. T., Alpaydın Baslo, S., Baslo, M. B., (2021). Jitter Ölçümünde Önemli Bir Gösterge: Ardışık Bloklar, Mühendislik Bilimleri ve Tasarım Dergisi, 9(1), 88-98.
}

\footnotetext{
* ilgili yazar / Corresponding author: tugrulartug@arel.edu.tr, +90-850-850-2735
} 
Yazar Kimliği / Author ID (ORCID Number)

N. T. Artuğ, 0000-0002-9259-2458

S. A. Baslo, 0000-0002-4096-3552

M. B. Baslo, 0000-0003-1551-0559
Makale Süreci / Article Process

Başvuru Tarihi / Submission Date

Revizyon Tarihi / Revision Date

Kabul Tarihi / Accepted Date

Yayım Tarihi / Published Date
15.01 .2020

07.01 .2021

22.01 .2021

30.03 .2021

\section{Giriş (Introduction)}

Sinir dalları kas liflerine bağlanmışlardır. Her kas lifi bir motor sinir tarafından inerve edilebilir (Daube ve Rubin, 2009). Ĕger bir sinir eşik değerinin üzerinde uyarılırsa aksiyon potansiyeli oluşur. Sinirden kasa aksiyon potansiyelinin iletimi 0.5 ile 1ms arasında zaman almaktadır. Nöromüsküler hastalıklar bu iletimi etkiler, dolayısıyla bu zaman uyarıdan uyarıya değișmektedir. Bu değișintiye "Jitter" adı verilir ve mikro saniye ile ifade edilir (Sanders ve Stålberg, 1996).

Ardışık sinir uyartımına karşılık yanıt ve uyartımın kendisi tek lif EMG (TLEMG) elektrodu ile kaydedilir. Bu elektrot gelişmiş bir elektrot türüdür. Bu elektrot ve onun ölçüm teknikleri Stålberg ve Ekstedt tarafından geliştirilmiştir (Stålberg ve Trontelj, 1994; Ekstedt, 1964). Bu elektrodun alma bölgesi çok küçük olduğundan sadece birkaç kas lifinden aksiyon potansiyeli kaydedebilir. TLEMG elektrodu pahalı bir elektrottur ama tekrar tekrar kullanılabilir. Elektrodun dezenfekte etme işlemi elektrodun ömrünü azaltmaktadır. Ayrıca tekrar kullanılmasından ötürü bazı ülkelerde bu elektrodun kullanımı yasaktır (Sarrigiannis vd., 2006; Benatar vd., 2006). Bu sebeplerden ötürü tek kullanımlık konsantrik iğne elektrotları (CNE) da jitter ölçümü için son zamanlarda kullanılmaya başlamıștır (Ertaş vd., 2000).

Jitter ölçülürken kas istemli olarak kasılır ve iki tek lif aksiyon potansiyeline ihtiyaç vardır. Yüksek genliğe sahip olan pik tetik olarak belirlenir. Eğer iki pik de aynı motor üniteye ait ise ikinci pik benzer konumlarda ileriye veya geriye hareket etmektedir (Sanders ve Stålberg, 1996). Aynı motor üniteye ait pik çifti bulunmadıkça sinyal kaydı alınmaz. Bir diğer jitter ölçme yönteminde ise elektriksel uyartım yapılır ve uyartı ile yanıt arasındaki süre ölçülür (Sanders ve Stålberg, 1996). İdealde analiz yapabilmek için bir oturumda 100 sinyal kaydı alınmaktadır (Kouyoumdjian ve Stålberg, 2008).

Jitter değeri mikro saniye ile ifade edilir. Jitter'in hesaplanması için ilk önce her sinyal için iki pikin konumları arasındaki mesafe farkı hesaplanır. Daha sonra kayıt sırasına göre bu fark değerlerinin ardışık farkları hesaplanır. Son olarak bu değerlerin ortalaması bulunur. Bu değer ortalama ardışık fark olarak adlandırılır (mean consecutive difference - MCD) (Sanders ve Stålberg, 1996). Jitter değeri sağlıklı bir birey için extensor digitorum communis

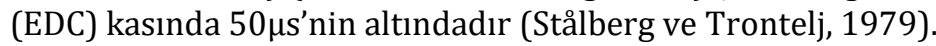

Kayıt sırasında zaman zaman sinirsel uyartıya karşılık yanıt gözlenmez. Bunun sebebi motor son plağı etkileyen hastalıklardır ve bu durum blok olarak adlandırılır. Bloklar sağlıklı bir bireyde gözlenmezden, nöromüsküler hastalıklardan muzdarip bireylerin kayıtlarında ardışık uyarıya karşılık görülebilmektedir (Sanders ve Stålberg, 1996).

Makalenin ikinci bölümünde literatür taraması bulunmaktadır. Üçüncü bölüm kullanılan yöntem ve materyali içerirken, dördüncü bölüm çalışmanın sonuçlarını barındırmaktadır. Çalışma beşinci bölüm olan sonuç ve tartışma ile son bulmaktadır.

Bu çalışma Sağlık Bilimleri Üniversitesi, Bakırköy Prof. Dr. Mazhar Osman Ruh Sağlığı ve Sinir Hastalıkları Eğitim ve Araştırma Hastanesi etik kurul komitesi tarafından onaylanmıştır (2019/348).

\section{Kaynak Araştırması (Literature Survey)}

Nöromüsküler iletim ileri derecede bozulduğunda, sinir impulsları kas aksiyon potansiyelleri ortaya çıkarmada başarısız olurlar ve TLEMG iğnesi ile kayıt alındığında kesik kesik impuls bloklanması görülür. Artan jitter ve sık bloklanmalar motor nöron rahatsızlığı olan hastalarda birçok çalışmada görülür (Sanders ve Howard, 1986).

Sanders ve Stålberg'in 1996 yılındaki TLEMG adına yapmış oldukları kapsamlı çalıșmada (Sanders ve Stålberg, 1996) TLEMG yönteminin detaylarını ve önemini göstermişlerdir. Miyasteni gravis (MG) hastası olan 788 kişilik bir grubun extensor digitorum communis kasından yaptıkları TLEMG kayıtlarında ocular MG için ortalama $41 \mu \mathrm{s}$ jitter ve \%5 blok oranı, genelleştirilmiş MG için ise ortalama $88 \mu$ s jitter \%28 blok oranı rapor etmişlerdir.

Valls-Canals ve diğerleri 2003 yılında 20 ocular MG hastası ile 46 sağlıklı bireyin frontalis ve orbicularis oculi (00) kaslarından elektriksel uyartım ile TLEMG elektrodu kullanarak kayıt almışlardır (Valls-Canals vd., 2003). Her 
oturumda 100 sinyal kaydetmişlerdir. Sağlıklılarda frontalis kasında jitter değerini MCD olarak $14,7 \pm 2,8 \mu$ s olarak bulmuşlardır. Aynı değer 00 kasında 12,56 $\pm 2,19 \mu$ s olarak hesaplanmıștır. MG hastaları için frontalis kasında jitter değeri 43,85 $\pm 25,18 \mu \mathrm{s}$, 00 kasında ise $69.85 \pm 29.55 \mu \mathrm{s}^{\prime}$ dir. Sağlıklı bireylere ait kayıtlarda bloklanma görülmemiștir. MG hastalarının blok sayısını yüzde olarak vermişlerdir. Alınan hasta kayıtlarında frontalis kası için sinyallerin $\% 2,18 \pm 3,02$ 'sinde, 00 kasında ise $\% 4,91 \pm 4,52$ blok görülmüştür.

2011'de Kouyoumdjian ve arkadașlarının yapmıș olduğu çalıșmanın amacı extensor digitorum (ED) ve frontalis kaslarında konsantrik iğne kullanarak Jitter parametreleri çalışmaktır (Kouyoumdjian vd., 2011). Veri setlerinde 20 'şer adet miyasteni gravis hastası ve sağlıklı birey bulunmaktadır. Verileri analize kabul ederken bazı kriterler uygulamışlardır. Bunlar sinyalin hızlı bir yükselme zamanı olması, çentiği veya omuzu olmaması, ardışık deșarjlarda süperempoze edildiğinde paralel yükselme zamanları olmasıdır. Ayrıca pikler birbirinden $150 \mu s^{\prime}$ den daha büyük bir zamanla ayrılmalı, piklerin șekli iyi tanımlanabilir olmalıdır. Jitter değerini frontalis kasında sağlıklı kontroller için 16,05 $\pm 2,73$ s olarak hesaplamışlardır. Sağlıklı bireylerin sadece frontalis kasından ölçüm yapmışlardır. Aynı değer MG hastaları için frontaliste 63,3 $\pm 32,1 \mu$ s olarak, ED kasında ise $61.5 \pm 50.8 \mu$ s olarak bulunmuştur. Sağlıklı bireylerde bloğa rastlanmamıștır. Frontalis kası için ocular MG grubunda \%23,3, ED kası için ise \%21,6 blok hesaplanmıştır. Genelleştirilmiş MG'de ise bu değerler sırasıyla \%38,3 ve \%31 olarak bulunmuştur. Elektriksel uyartımda yüksek toplam riski olduğunu çünkü birçok aksonun sıkça uyarıldığını belirtmişlerdir. Konsantik iğne ile jitter analizi yapılacaksa istemli kasıyı tavsiye etmişler ve geniş uzuv kaslarından uyartım çalışmaları için kaçınılması gerektiğini söylemişlerdir.

Stålberg ve diğerlerinin yapmıș olduğu çalıșmanın amacı konsantrik iğne ile yapılan istemli kası veya elektriksel uyartım tekniklerini göstermek ve karşılaşılabilecek tuzakları tanımlamaktır (Stålberg vd., 2017). Konsantrik iğne elektrodu ile yapılan kayıtlarda sinyallerin kabulü için uyulması gereken kriterleri şöyle sıralamışlardır: sinyalin çentiği veya omuzu olmamalı, sinyaldeki pik hızlı yükselmeli ve ardışık deşarjlarda sinyal formunu korumalıdır. Kesik kesik bloklanma olmasının jitter'i arttırdığını söylemişlerdir. Bunun önüne geçmek için ise sinyallerin iki piki arasındaki ardışık zaman farklarının küçükten büyüğe dizilmesi gerektiğini belirtmişlerdir. Jitter değeri bu dizilmiş veriden hesaplanır ve buna ortalama dizilmiş fark (MSD) adı verilir.

Bu çalışmada, hesaplanan geleneksel jitter parametrelerin yanında diğer çalışmalarda yapılanlardan farklı olarak hastalıkların seyrine yönelik bir fikir vereceği öngörülen ardışık blok gruplarını ve ardışık blok gruplarındaki maksimum blok sayısını hesaplayan bir yazılım geliştirilmiştir. Ardışık blok grubu davranışlarının kastan kasa ve hastalığa göre değişmesi ayırıcllı̆̆ arttırabilecek ve klinisyenlere kolaylık sağlayabilecektir.

\section{Materyal ve Yöntem (Material and Method)}

Yedi sağlıklı kontrol ve 6 miyasteni gravis hastasını içeren bir veri seti olușturuldu. Kayıt alınırken belli kriterlere uyuldu. Bu kriterler; tetik olarak her zaman en büyük genlikli pik seçildi ve en büyük genlikli pik ile ikinci pik arasındaki genlik oranının \%30'dan daha az olmamasına dikkat edildi. Jitter ölçümü için sinyaller her oturumda 100 adet olmak üzere, istemli kası sırasında CNE kullanılarak frontalis kasından kaydedildi.

Bu çalışmada birçok özelliği olan çok yönlü bir yazılım geliştirilmiştir. Jitter değerini ortalama ardışık fark (MCD) veya ortalama sıralanmış fark (MSD) olarak hesaplayabilmektedir. Tetik olarak seçilen potansiyelin konumuna göre ikinci pikin en yakın ve en uzak konumları arasındaki fark 100 sinyal arasından kontrol edilip bulunmaktadır. Böylece ikinci pikin oynaklık menzili tespit edilmektedir. Bu değere potansiyel arası mesafe (IPI range) adı verilmektedir. Yazılım ile impuls bloklarının sayısı hesaplanabilirken, ayrıca ardışık blok grupları da gösterilebilmektedir. Bu yazılımın benzersiz özelliklerinden birisi de jitter'in sesini dinleyebilmeyi mümkün kılmasıdır (Alpaydin Baslo vd., 2019).

EMG cihazını ile kaydedilen veriler "txt" formatı ile dışarı alınabilmektedir. Bu veriler kullanılabilmek için öncelikle daha önceden geliştirilmiş olan bir algoritma (Artuğ, 2015) ile ön işlemlere tabi tutulmalı ve işaret işlemeye hazır hale getirilmelidirler. Daha sonra sinyaller geliştirilen algoritma tarafından okutulur ve sinyaller üzerine dalgacık temelli gürültü giderme işlemi uygulanır. Kullanıcı tarafından çalışılan kas ve iğne elektrot tipi seçilir. Her sinyal için en yüksek genlik veren iki pikin konumu ve genlikleri belirlenir. Sinyallerin blok mu değil mi olduğu kontrol edilir. Eğer sinyallerde blok olan varsa işaretlenir. Tüm sinyallerin kontrolü bittikten sonra blok sayısı hesaplanır ve ardışı blok grupları belirlenir. Blok gruplarının adedi ve içerdikleri blok sayısı da ayrı ayrı hesaplanıp kullanıcıya gösterilir. Jitter değeri MCD olarak hesaplanır. Blok olmayan sinyaller kayıtlardan ayıklandıktan sonra potansiyel arası mesafe (IPI range) hesaplanır. Bu hesaplamalardan sonra kullanıcıya jitter grafiği, ardışık zaman farklarının küçükten büyüğe dizilmesiyle oluşan grafik, ikinci pikin oynaklığının grafiği gibi çeşitli grafikler gösterilir. Jitter'in sağlıklı bir kontrole ve MG hastasına göre değişimi Şekil 1'de gösterilmiştir. 


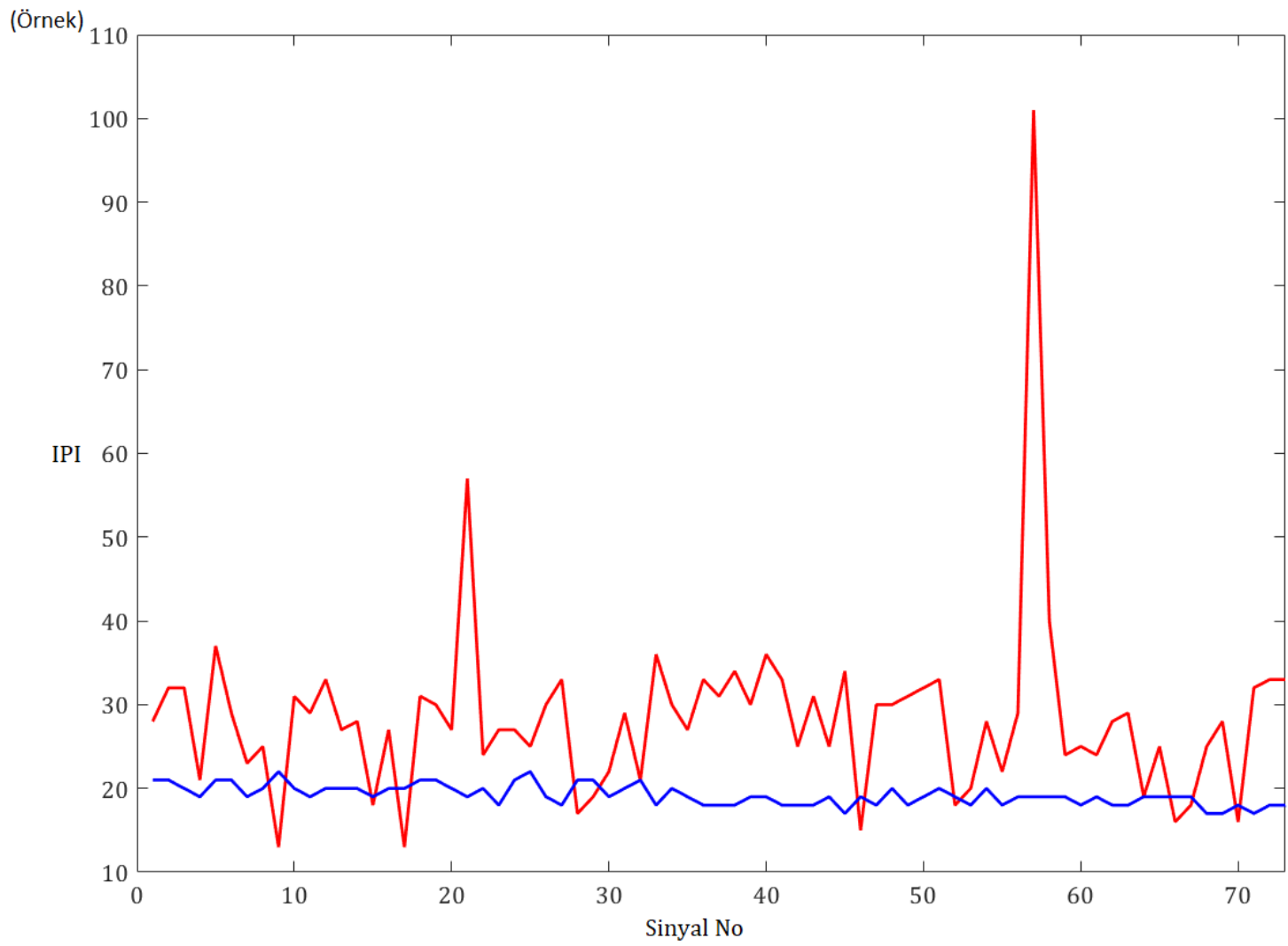

Şekil 1. Sağlıklı kontrol (mavi) ve MG hastası (kırmızı) için jitter değişimi (The change of jitter for healthy controls (blue) and MG patients (red))

Sağlıklı bir bireye ve MG hastasına ait alınan kayıtlardan elde edilen ardışık zaman farklarının küçükten büyüğe dizilmesiyle oluşan grafik ise Şekil 2 ve 3 'te gösterilmiştir.

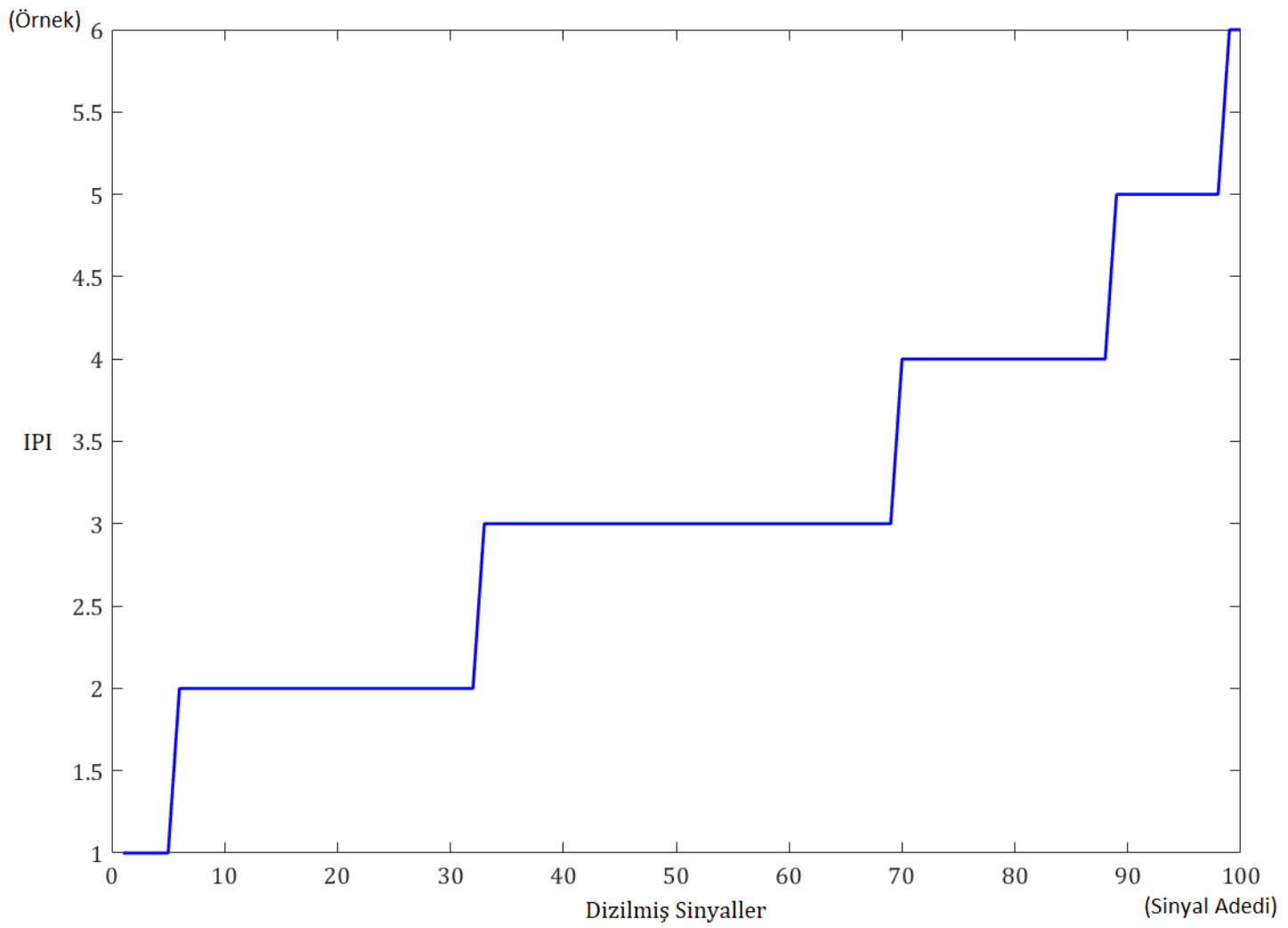

Şekil 2. Sağlıklı bir bireyin kayıtlarından elde edilen IPI değerlerinin küçükten büyüğe dizilmesi sonucu oluşan grafik (The graphic which represents the sorting of IPI values in ascending order for the recordings that are acquired from a healthy individual) 


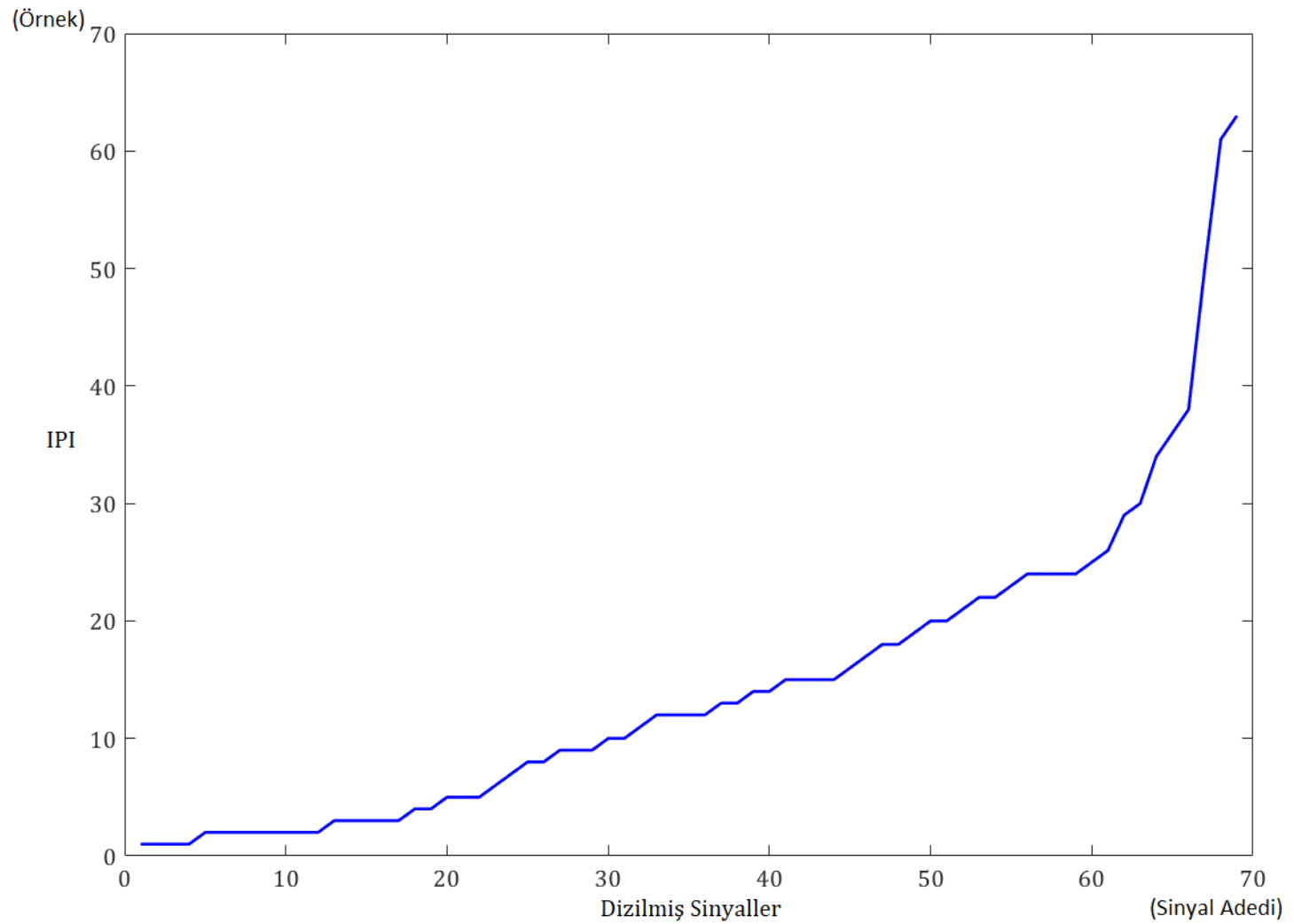

Şekil 3. MG hastasının kayıtlarından elde edilen IPI değerlerinin küçükten büyüğe dizilmesi sonucu oluşan grafik (The graphic which represents the sorting of IPI values in ascending order for the recordings that are acquired from an MG patient)

İki kaydın şekilleri incelendiğinde MG hastası için değişimin fazlalığı görülmektedir. İkinci pikin oynaklığının grafiği ise sağlıklı bir kontrol için Şekil 4'te, MG hastası için Şekil 5'te sunulmuştur.

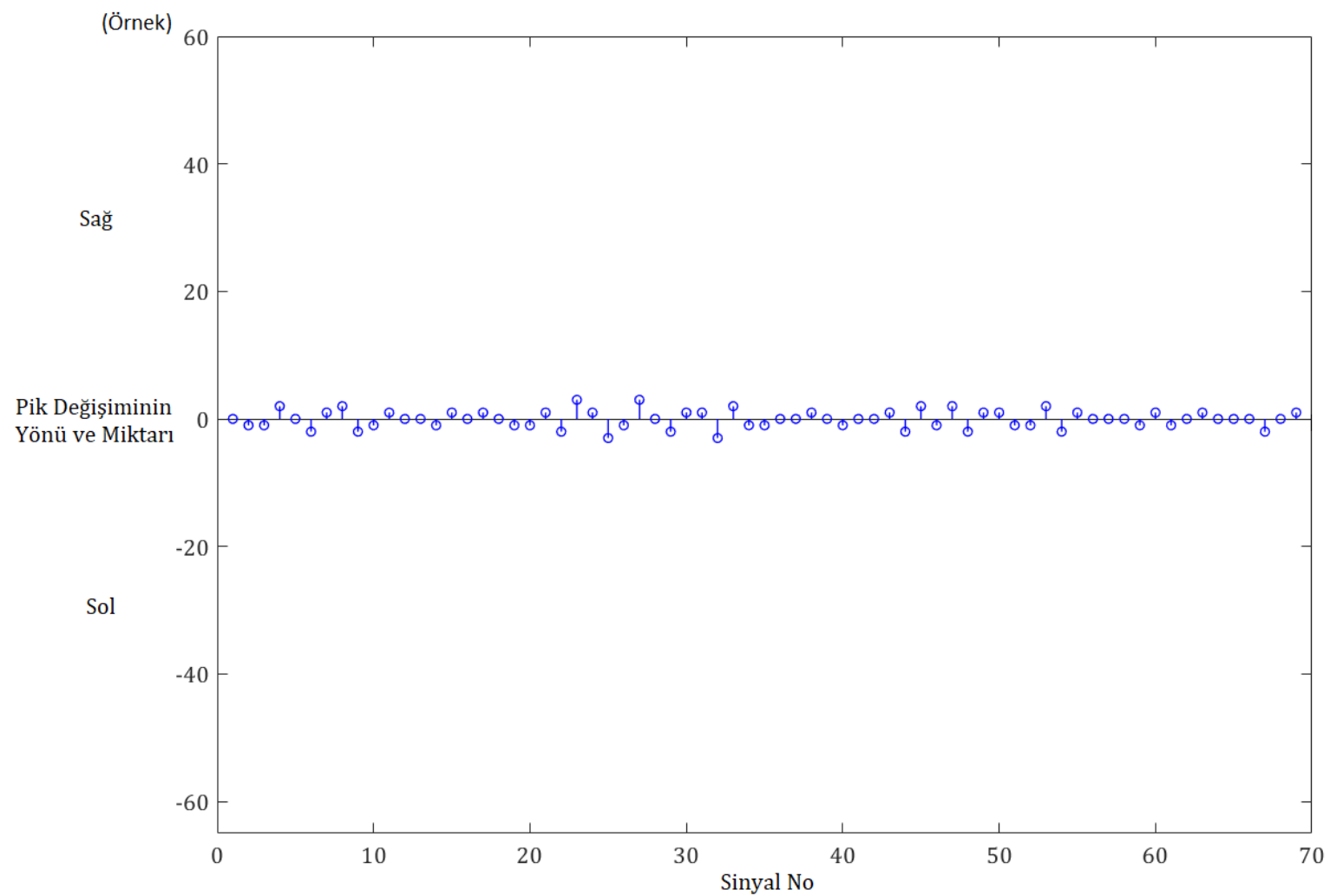

Şekil 4. Sağlıklı bir bireyde ikinci pikin sola ve sağa konum değişimi ve miktarı

(The location and amount change to the left and right for the second peak in a healthy individual) 


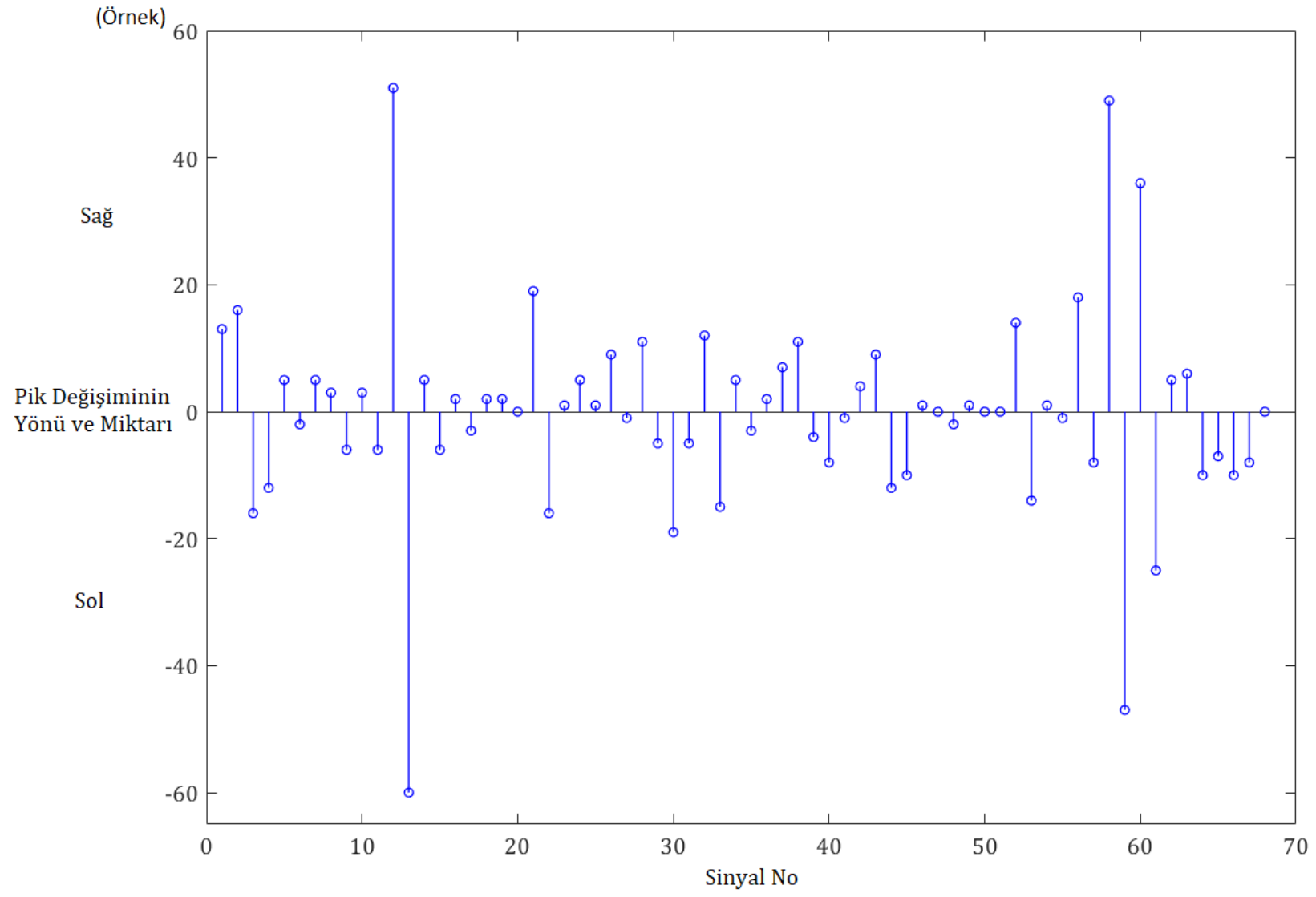

Şekil 5. Bir MG hastasında ikinci pikin sola ve sağa konum değişimi ve miktarı

(The location and amount change to the left and right for the second peak in an MG patient)

Bu grafiklerin gösteriminden sonra, belirlenen iğne ve kas tipine göre kavşă̆ın durumunun normal veya hasta olduğu bilgisi ekrana verilir.

Son olarak elde edilen verilerden o kayıt için algoritma tarafından jitter'in sesi üretilir (Alpaydin Baslo vd., 2019).

Algoritmanın akış şeması Şekil 6'da özet olarak verilmiștir.

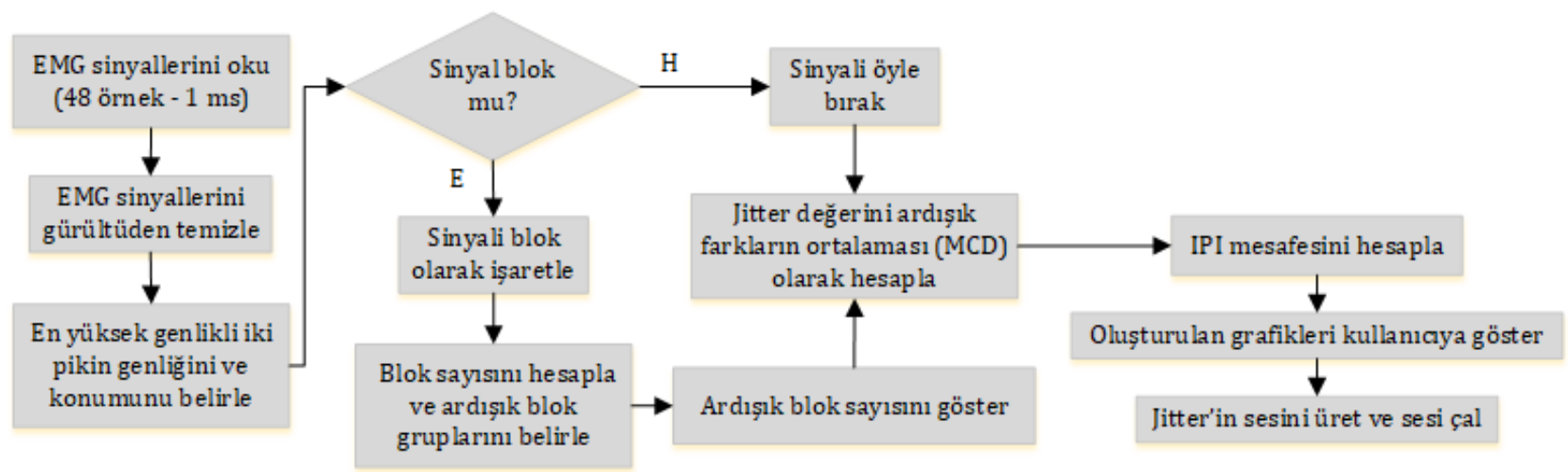

Şekil 6. Algoritmanın akış şeması (Flow chart of the algorithm)

Sağlıklı bir kontrole ait 5 sinyal üst üste bindirildiğinde oluşan görüntü Şekil 7'de verilmiştir. Bir miyasteni gravis hastasına ait kayıtta ise benzer gösterim Şekil 8'de verilmiştir. 


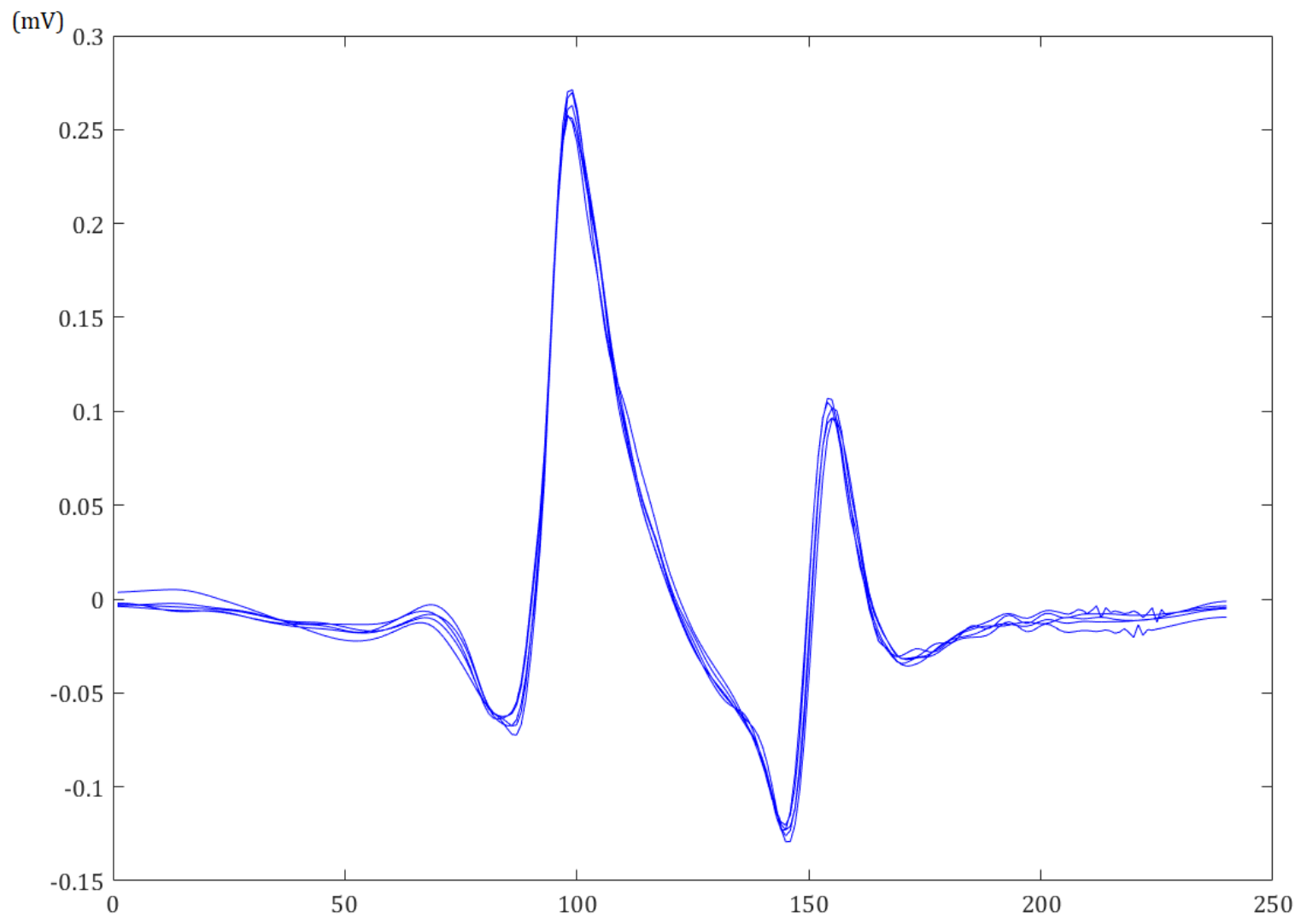

48 örnek = $1 \mathrm{~ms}$

Şekil 7. Normal bir birey için 5 sinyalin süperpoze edilmiş hali (The superposition of 5 signals for a normal individual)

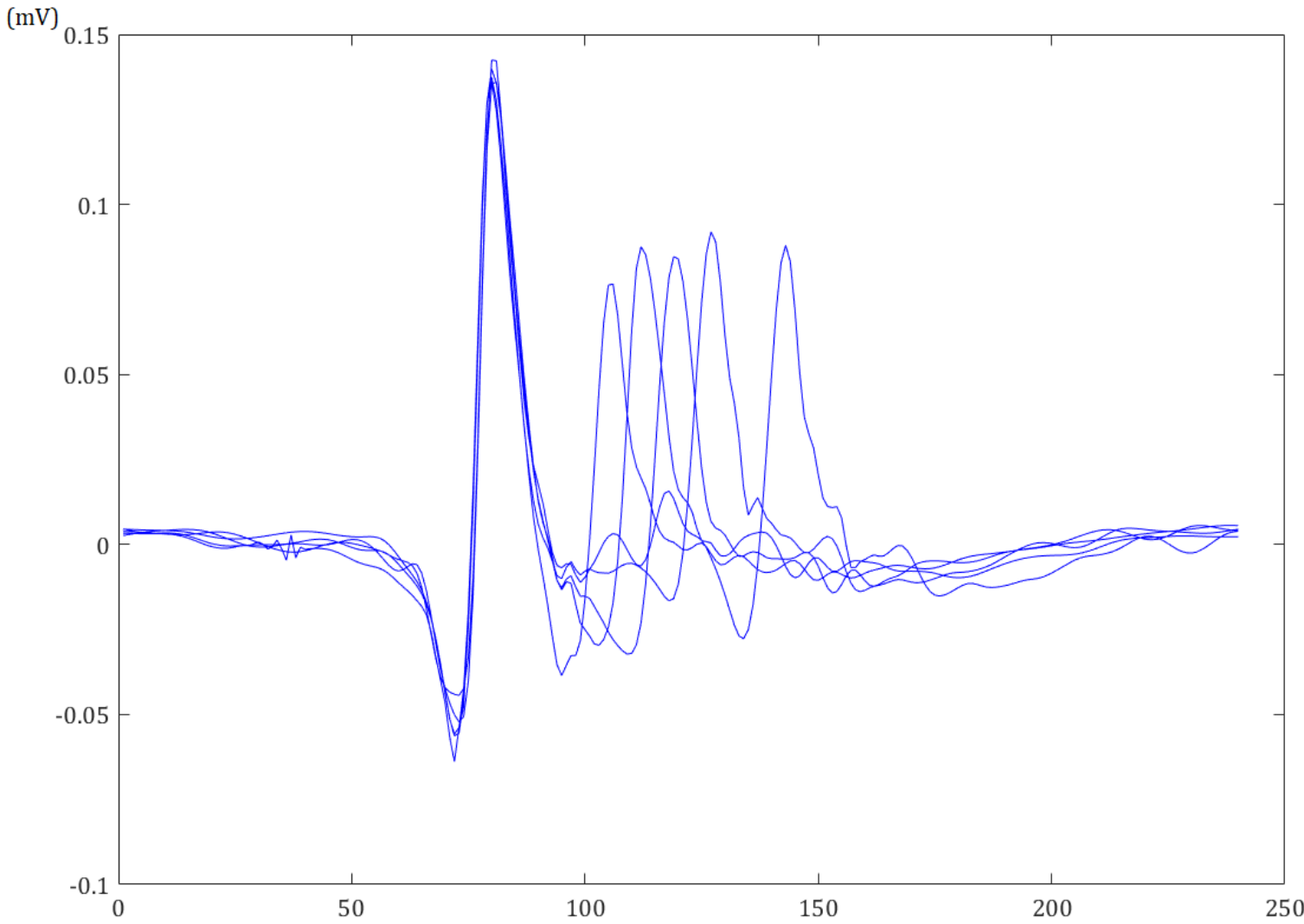

48 Örnek = $1 \mathrm{~ms}$

Şekil 8. Bir miyasteni gravis hastası için 5 sinyalin süperpoze edilmiş hali (The superposition of 5 signals for a myasthenia gravis patient) 


\section{Deneysel Sonuçlar (Experimental Results)}

Geliştirilen yazılım kullanılarak elde edilen jitter ölçümüne yönelik sonuçlar iki tablo halinde Tablo 1'de sunulmuştur.

Her oturumda 13 katılımcıdan 100 adet sinyal kaydı yapılmıș olsa da bu sinyallerin bazıları nadiren gürültülü olmaktadır. Düzeltilemeyecek seviyedeki böyle sinyaller analiz dışı bırakılmıştır. Sinyallerin atılmasından sonra kalan sinyal adedinde 95'in altına inilmemiştir.

Tablo 1. Jitter ölçümü için hesaplanmıș parametreler (The calculated parameters for jitter measurement)

\begin{tabular}{|c|c|c|c|c|c|c|c|}
\hline & $\begin{array}{l}\text { Kişi } \\
\text { No \# }\end{array}$ & $\begin{array}{l}\text { Sinyal } \\
\text { Sayı1 }\end{array}$ & $\begin{array}{c}\text { Jitter } \\
\text { (MCD) } \\
(\mu \mathrm{s})\end{array}$ & $\begin{array}{c}\text { IPI } \\
\text { Mesafesi } \\
(\mu s)\end{array}$ & $\begin{array}{c}\text { Blok } \\
\text { Sayısı }\end{array}$ & $\begin{array}{c}\text { Blok } \\
\text { Gruplarının } \\
\text { Sayısı }\end{array}$ & $\begin{array}{c}\text { Maksimum } \\
\text { Ardışık } \\
\text { Blok Sayısı }\end{array}$ \\
\hline \multirow{7}{*}{$\begin{array}{c}\text { Sağlıklı } \\
\text { Kontroller }\end{array}$} & 1 & 97 & 42,53 & 229,17 & 0 & 0 & 0 \\
\hline & 2 & 100 & 20,41 & 104,17 & 0 & 0 & 0 \\
\hline & 3 & 100 & 8,63 & 62,5 & 0 & 0 & 0 \\
\hline & 4 & 99 & 48,68 & 312,5 & 0 & 0 & 0 \\
\hline & 5 & 100 & 21,25 & 83,33 & 0 & 0 & 0 \\
\hline & 6 & 100 & 19,78 & 104,17 & 0 & 0 & 0 \\
\hline & 7 & 95 & 10,2 & 41,67 & 0 & 0 & 0 \\
\hline \multirow{6}{*}{$\begin{array}{c}\text { Miyasteni } \\
\text { Gravis } \\
\text { Hastaları }\end{array}$} & 8 & 98 & 145,11 & 1062,5 & 11 & 2 & 3 \\
\hline & 9 & 99 & 144,43 & 1166,67 & 24 & 5 & 4 \\
\hline & 10 & 96 & 122,92 & 520,83 & 25 & 4 & 3 \\
\hline & 11 & 100 & 182,58 & 1833,33 & 27 & 5 & 5 \\
\hline & 12 & 100 & 207,11 & 1291,67 & 31 & 7 & 4 \\
\hline & 13 & 98 & 173,61 & 791,67 & 40 & 9 & 7 \\
\hline
\end{tabular}

Jitter değeri için ortalama değer sağlıklı kontrollerde 24,5 $\pm 15,36 \mu$ s, miyasteni gravis hastalarında ise 162,63 \pm 30,7 $\mu$ s olarak hesaplanmıştır.

IPI mesafesi parametresi ikinci pikin tetiğe ne kadar yaklașıp ne kadar uzaklașabileceğini, diğer bir değișle oynaklığının menzilini veren bir göstergedir. Bu değer ortalama sağlıklı kontrollerde 133,93 \pm 99,08 $\mu$ s olarak bulunmuştur. Aynı parametre MG hastalarında 1111,11 $\pm 449,47 \mu$ s olarak hesaplanmıștır.

Sağlıklı kontrollerde beklendiği gibi bloğa rastlanmamıştır.

MG hastaları için ise blok sayısının ortalama değeri 26,33 \pm 9,5 olarak bulunmuștur.

MG hastalarında ayrıca ardışık blok gruplarına rastlanmıştır. Bu parametre için ortalama değer 5,33 $\pm 2,42$ bulunmuştur. Bir kayıtta görülen en fazla ardıșık blok grubu sayısı 9 olarak gözlenmiştir.

Hesaplanan son parametre maksimum ardışık blok sayısıdır. Ortalama değer bu parametrede 4,33 \pm 1,51 olarak elde edilmiştir. En fazla 7 blok arka arkaya çıkmıştır.

Şekil 9'da bloklar çubuk olarak gösterilmiştir. Blok sayısı bu kayıt için 11 olarak bulunmuştur. Ayrıca şekilde ardışık blok grupları da daireler ile gösterilmektedir. Şekil 9 için ardışık blok grubu sayısı 2'dir ve maksimum ardışık blok sayısı ise yine 2 olarak bulunmuştur. 


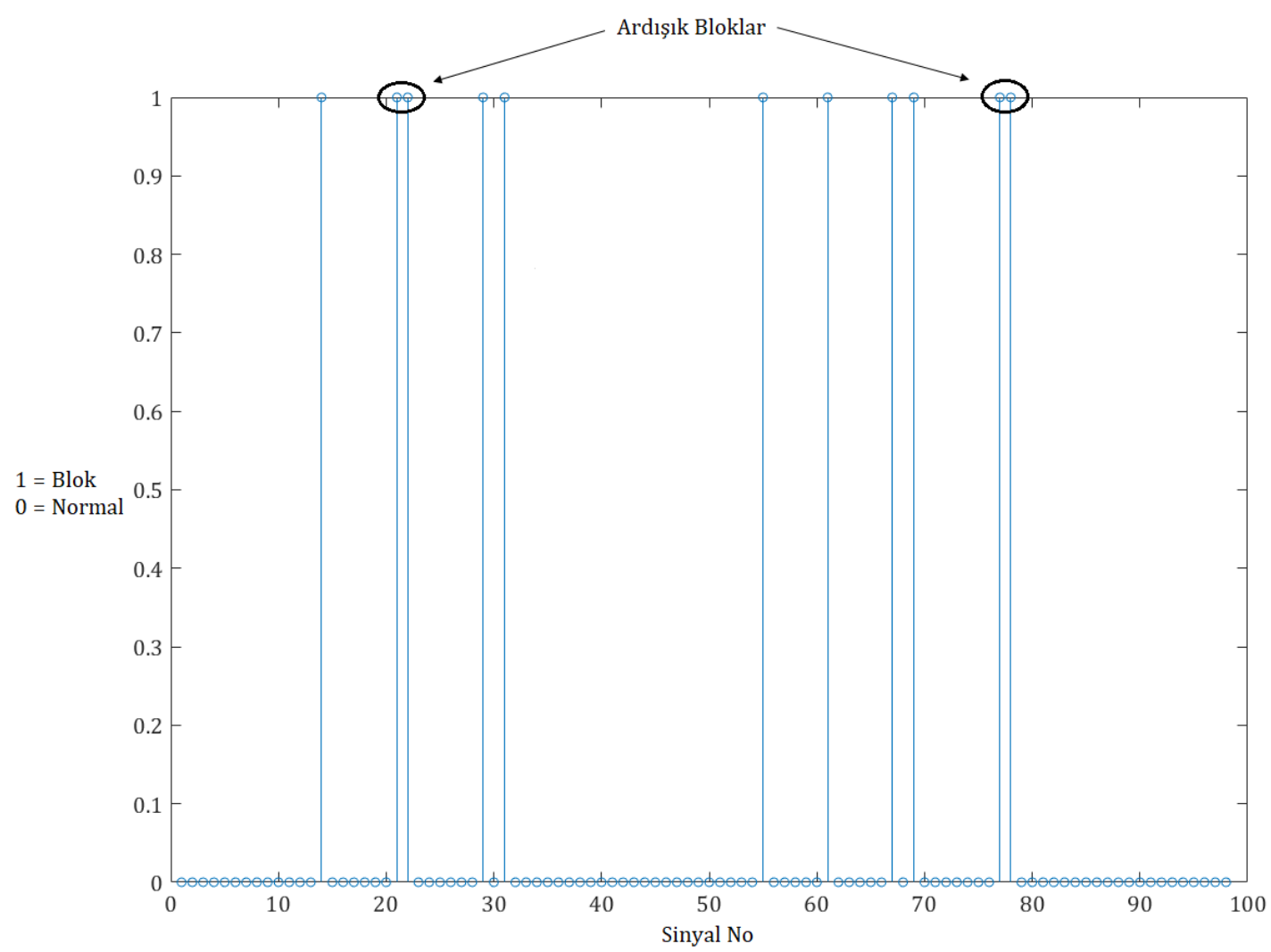

Şekil 9. Bloklar ve ardışık blok grupları (Blocks and consecutive block groups)

\section{Sonuç ve Tartıșma (Result and Discussion)}

Bu çalışmada sağlıklı bireylerden ve miyasteni gravis hastalarından jitter çalışmaları yapmak üzere veriler kaydedilip bir veri seti olușturulmuştur. Yeni geliştirilmiş bir yazılım ile jitter çalışmalarına yönelik hesaplamalar yapılmış ve sinyaller ile hesaplanan parametrelere yönelik grafikler gösterilmiştir. Sağlıklı kontroller için hesaplanan tüm jitter değerleri limit değer olan $50 \mu$ s'den küçük çıkmıştır. Aksine MG hastaları için minimum jitter değeri 122,92 $\mu$ s olarak gözlenmiștir. IPI mesafesi MG hastaları için beklendiği üzere daha uzun çıkmıștır. Bu değer sağlıklı kontrollerde minimum 41,67 $\mu \mathrm{s}$, MG hastalarında ise 520,83 $\mu$ s olarak elde edilmiştir. Sağlıklı bireylerde hiç bloğa rastlanmamıştır. Yüksek sayıda blok MG hastalarının kayıtlarında gözlenmiş̧tir. Ardışık blok grupları yazılımın yardımıyla gözlemlenebilmiştir.

Sanders ve Stålberg'in çalışması TLEMG yöntemini tanıtmak için çok önemli bir çalışmadır (Sanders ve Stålberg, 1996). Hasta grubunun hastalık türü aynı olsa da hem iğne türü hem de ölçüm yapılan kas aynı olmadığından karşılaştırma yapmak mümkün değildir.

Valls-Canals ve diğerlerinin yaptığı çalışmada (Valls-Canals vd., 2003) elektriksel uyartım tekniği ile TLEMG elektrodu kullanılmıştır. Elektriksel uyartımda jitter değeri istemli kasıya oranla daha az çıkmaktadır. Bunun sebebi jitter değerinin tek bir motor son plağın aktarımını yansıtmasıdır (Sanders ve Stålberg, 1996). Bir çalışmada elektriksel uyartım ile elde edilen jitter değerinin ortalamasının istemli kasıya oranla \%28 daha az çıktığını rapor etmişlerdir (Jabre vd., 1989). Yaptıkları çalışmada her ne kadar kullanılan iğne bakımından doğrudan örtüşme olmasa da ölçüm tekniğindeki bu fark da hesaba katıldığında sağlıklılar için elde ettikleri 14,7 $\mu$ s MCD değeri ile bu çalışmada elde edilen 24,5 us MCD değeri yakındır. Hastalar için elde edilen jitter değerinde ise örtüşme yoktur. Bunun sebebi bu çalıșmadaki hasta grubunun hastalık seyrinin daha ileri bir safhada olması olabilir.

Kouyoumdjian ve arkadaşlarının çalışmasında ölçüm yapılan kas ve kullanılan elektrot tipi bu çalışma ile örtüşmektedir (Kouyoumdjian vd., 2011). Konsantik iğne kullandıklarından dolayı aynı bu çalışmada olduğu gibi bazı kriterlere dikkat ederek kayıt almışlardır. Kontroller için frontalis kasında ortalama 16,05 $\mu$ s jitter ölçmüşlerdir. Aynı değer bu çalışmada 24,5 $\mu$ s olarak bulunmuştur. Veri seti nispeten daha az kayıt içerdiğinden jitter değer ortalaması yüksek bulunsa da limit değerin altındadır. MG hastaları için bulunan jitter değeri ise karşılaştırılan çalışmadan daha yüksek 162,63 s olarak elde edilmiştir. Sağlıklı bireylerde bloğa rastlanmazken, MG grubunda elde ettikleri \%23,3 blok oranına karşlık bu çalışmada \%26,73 blok oranı bulunmuştur. Blok açısından karşılaştırılan değerler uyum içindedir.

Kouyoumdjian ve Stålberg 2013 yılında yine bu çalıșmada incelenen aynı kas üzerinde çalıșma yapmıșlardır 
(Kouyoumdjian ve Stålberg, 2013). Kayıtlar istemli kası altında konsantrik iğne ile yapılmıştır. Olușturdukları veri seti 20 sağlıklı bireye ait kayıtlar içermektedir. Analize alınacak verilerdeki piklerin kısa yükselme zamanlı, iyi tanımlanan ve sabit şekilli olmalarına dikkat etmişlerdir. Aldıkları 20 kayıt için yaptıkları analiz sonucu hesaplanan MCD değerlerinin ortalaması 19,9 $\mu$ s olarak bulunmuştur. Bu çalışmada ise hesaplanan değer 7 sağlıklı birey için ortalama $24,5 \mu s^{\prime}$ dir. Hesaplanan ortalama değerler yakın bulunmuştur.

Sanders ve diğerlerinin 2019 yılında yaptıkları kapsamlı çalışma TLEMG metodunu tüm detayıyla anlatmaktadır (Sanders vd., 2019). Jitter ölçümü için TLEMG iğnesi en ideal elektrot olsa da konsantrik elektrot ile de belirli kayıt kriterlerine uyarak çalışma yapılabileceği açıkça belirtilmiştir. Bu kriterlerden bazıları yüksek geçiren filtrenin kesim frekansını 1 veya $2 \mathrm{KHz}$ olarak ayarlamak, arka arkaya yapılan kayıtlarda alınan sinyal şeklinin tutarı olması ve kısa yükselme zamanına sahip pikleri analiz için tercih etmektir. Bu çalışmada yapıldığı gibi otomatik sinyal işleme tekniklerinin geliştirilmesi ile sinyallerin üzerindeki gürültünün tespit edilip giderilmesi ve sinyallerin kalitesinin değerlendirilmesinin otomatize edilerek operatör yükünün azaltılması ihtiyacının önemi vurgulanmıştır.

Musa ve Ahmed'in 57 sağlıklı birey üzerinde yaptıkları çalıșmada orbicularis oculi ve frontalis kaslarından konsantrik iğne ile istemli kası sırasında kayıt almışlardır (Musa ve Ahmed, 2020). Bir oturumda minimum 50 olmak üzere 50 ile 100 adet arası sinyal kaydını analiz için şart koşmuşlardır. Frontalis kası için hesaplamış

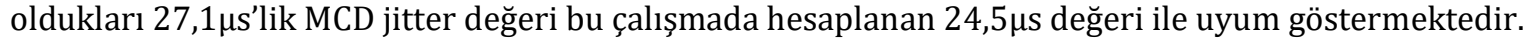

Yapılan hiçbir çalışmada ardışık blok grubu veya maksimum ardışık blok sayısı gibi parametrelerin ölçüldügüne rastlanmamıştır. Bu çalışma diğer çalışmadan sadece bu yönüyle değil elde edilen jitter değerlerinin değişimini sese çevirmesi özelliği ile de farklılığını göstermektedir.

Blok sayısının artması ve ardışık blok gruplarına rastlanmasının hastalı̆̆ın seyrinin ağırlığı konusunda bir gösterge olduğu ön görülmektedir. Sonuçlara bakıldığında artan jitter değerine rağmen IPI mesafesinin zaman zaman aynı oranda artmadığı, hatta daha düşük bir jitter değerine göre daha az IPI mesafesi hesaplandığı görülmektedir. Bunun sebebi jitter ile IPI mesafesi arasındaki bağıntının belli bir değere kadar doğrusallı̆ını sürdürmesidir. Jitter değerinin $150 \mu$ s'yi geçmesiyle blok ihtimali de artar. Artan blok da zaman zaman IPI mesafesinin kısalmasına sebep olmaktadır.

İlerleyen çalışmalarda veri seti büyütülecek ve farklı nöromüsküler hastalık türleri için de blok sayısı ile ardışık blok gruplarının davranışı incelenecektir. Yazılımın kabiliyetinin yeni özellikler eklenerek arttırılması da planlanmaktadır.

\section{Teşekkür (Acknowledgement)}

Yazarlar hastaların temini ve veri toplamasındaki değerli katkılarından dolayı Doç. Dr. Dilek Ataklı’ya teşekkür eder.

\section{Çıkar Çatışması (Conflict of Interest)}

Yazarlar tarafından herhangi bir çıkar çatışması beyan edilmemiştir. No conflict of interest was declared by the authors.

\section{Kaynaklar (References)}

Alpaydin Baslo, S., Artuğ, T., Şirin, N. G., Kocasoy Orhan, E., Baslo, M. B., 2019. Listening the Sound of Neuromuscular Junction during Voluntary Contraction. Abstracts / Clinical Neurophysiology, 130, e33.

Artuğ, N. T., 2015. Taramalı EMG ile Nöromüsküler Parametrelerin Belirlenmesi. Yayınlanmamıș Doktora Tezi. Yıldız Teknik Üniversitesi, Türkiye.

Benatar, M., Hammad, M., Doss-Riney, H., 2006. Concentric-needle single-fiber electromyography for the diagnosis of myasthenia gravis. Muscle Nerve, 34, 163-168.

Daube, J. R., Rubin, D. I., 2009. Needle electromyography. Muscle Nerve, 39, 244-270.

Ekstedt, J., 1964. Human single muscle fiber action potentials. Acta Physiol Scand Suppl., 226, 1-96.

Ertaș, M., Baslo, M. B., Yildiz, N., Yazici, J., Oge, A. E., 2000. Concentric Needle Electrode for Neuromuscular Jitter Analysis. Muscle Nerve, 23, 715-719.

Jabre, J. F., Chirico-Post, J., Weiner, M., 1989. Stimulation SFEMG in Myasthenia Gravis. Muscle Nerve, 12, 38-42.

Kouyoumdjian, J. A., Da Silva Fanini, A. C., Stålberg, E., 2011. Concentric Needle Jitter on Stimulated Frontalis and Extensor Digitorum in 20 Myasthenia Gravis Patients. Muscle Nerve, 44, 912-918.

Kouyoumdjian, J. A., Stålberg, E., 2008. Concentric needle single fiber electromyography: Comparative jitter on voluntaryactivated and stimulated Extensor Digitorum Communis. Clinical Neurophysiology, 119, 1614-1618. 
Kouyoumdjian, J. A., Stålberg, E., 2023. Concentric Needle Jitter on Voluntary Activated Frontalis in 20 Healthy Subjects. Muscle Nerve, 47, 440-442.

Musa, A. M. M., Ahmed, A. E. M., 2020. Reference Jitter Values for Concentric Needle Electrode of Orbicularis Oculi and Frontalis Muscles Using Voluntary Activation Method in Sudanese Population. Sci Rep, 10, 1031.

Sanders, D. B., Arimura, K., Cui, L., Ertaş, M., Farrugia, M. E., Gilchrist, J., Kouyoumdjian, J. A., Padua, L., Pitt, M., Stålberg, E., 2019. Guidelines for single fiber EMG. Clinical Neurophysiology, 130, 1417-1439.

Sanders, D. B., Howard, J. F., 1986. AAEE Minimonograph \#25: Single-Fiber Electromyography in Myasthenia Gravis. Muscle Nerve, 9, 809-819.

Sanders, D. B., Stålberg, E., 1996. AAEM Minimonograph \#25: Single-Fiber Electromyography. Muscle Nerve, 19, 1069-1083.

Sarrigiannis, P. G., Kennett, R. P., Read, S., Farrugia, M. E., 2006. Single-Fiber EMG with a Concentric Needle Electrode: Validation in Myasthenia Gravis. Muscle Nerve, 33, 61-65.

Stålberg, E., Sanders, D. B., Kouyoumdjian, J. A., 2017. Pitfalls and errors in measuring jitter. Clinical Neurophysiology, 128, 2233-2241.

Stålberg, E., Trontelj, J. V., 1979. Single Fibre Electromyography. Old Woking, UK, Mirvalle Press.

Stålberg, E., Trontelj, J. V., 1994. Single fiber electromyography: Studies in healthy and diseased muscle, second ed. New York, Raven Press.

Valls-Canals, J., Povedano, M., Montero, J., Pradas, J., 2003. Stimulated Single-Fiber EMG of the Frontalis and Orbicularis Oculi Muscles in Ocular Myasthenia Gravis. Muscle Nerve, 28, 501-503. 